Winter Meeting - Joint meeting between the Nutrition Society and the Royal Society of Medicine, 11-12 December 2012, Dietary Strategies for the Management of Cardiovascular Risk

\title{
Are vegetarians susceptible to primary cardiovascular disease, due to a lack or absence of dietary animal produce?
}

\author{
D. Obersby, D. C. Chappell and A. A. Tsiami
}

School of Psychology, Social Work and Human Sciences, University of West London, Brentford, Middlesex, TW8 9GA, UK

There are approximately four million vegetarians within the UK population ${ }^{(1)}$. Worldwide there are 75 million vegetarians by choice and 1450 million by necessity ${ }^{(2)}$. Whilst the vegetarian diet is accepted as a protection against cardiovascular disease, probably due to reduced saturated fat, lower cholesterol, lower prevalence of obesity and slightly lower blood pressure, there is however a high probability that it is deficient in vitamin B12 due to a lack or absence of dietary animal produce, which can elevate homocysteine ${ }^{(3)}$. This potentially dangerous sulphur containing amino acid, which is produced in every cell of the body, is capable of causing cellular damage, which includes the arterial endothelium that can enhance thrombogenicity ${ }^{(4)}$. There is indeed strong evidence indicating that elevated plasma total homocysteine (tHcy) levels are a contributor to chronic conditions, such as primary coronary heart disease (CHD) ${ }^{(3)}$ and stroke ${ }^{(5)}$.

The object of the study was to stratify a range of acceptable cohort studies that compare the plasma tHcy and serum vitamin B12 status of vegetarians and omnivores and to compile a systematic review and meta-analysis of which to-date there is no record of any publication.

Search methods employed identified 244 (2958 participants) entries from which by screening, using criteria revealed sixteen eligible cohort case study publications from 1999 to 2010 that compared the concentrations of plasma tHcy and serum vitamin B12 of omnivores, lactovegetarians or lactoovovegetarians (LV-LOV's) and vegans.

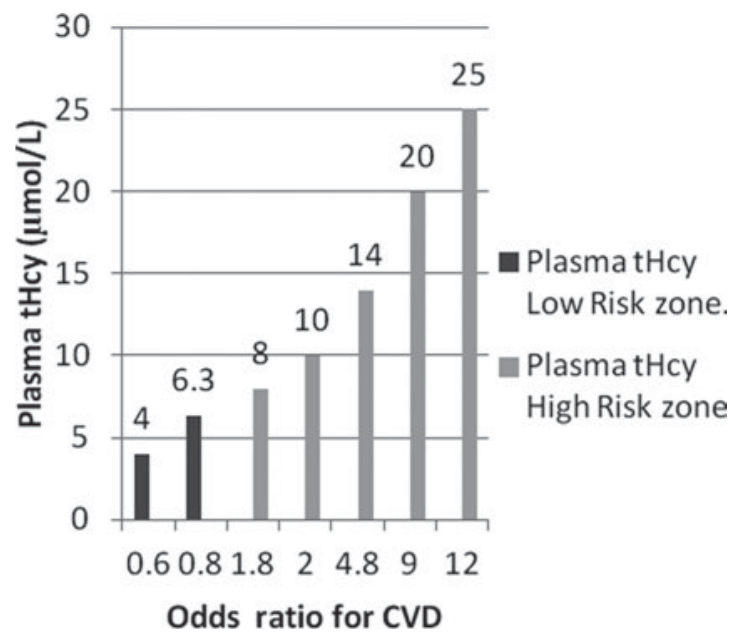

Fig. 1. Relative risk of CHD compared to plasma tHcy ${ }^{(6-8)}$.

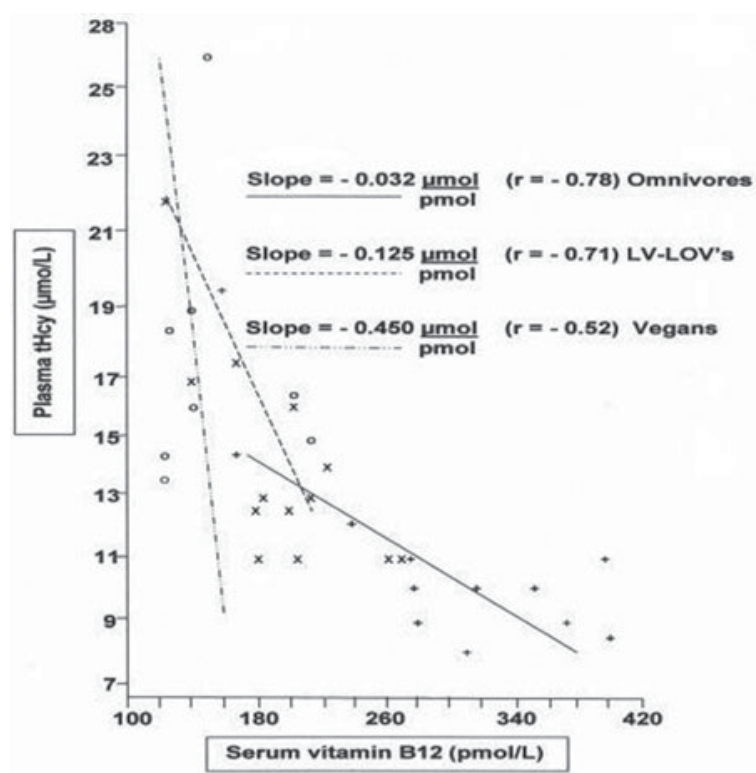

Fig. 2. Relationship between plasma tHcy and serum vitamin B12 for omnivores, LV-LOV's and vegans.

A further object was to focus on the relationship between levels of plasma tHcy and the risk of developing CHD. These findings are summarised in Figure 1.

Figure 2 confirms that an inverse relationship exists between plasma tHcy and serum vitamin B12. The meta-analysis revealed that vegans have a mean plasma tHcy of $16.4 \mu \mathrm{mol} / \mathrm{L}$ with a corresponding mean serum vitamin B12 of $172 \mathrm{pmol} / \mathrm{L}$ compared to LV-LOV's mean plasma tHcy of $14.0 \mu \mathrm{mol} / \mathrm{L}$ and mean serum vitamin B12 of $198 \mathrm{pmol} / \mathrm{L}$. Omnivores mean plasma tHcy was $10.9 \mu \mathrm{mol} / \mathrm{L}$ and mean serum vitamin B12 of $303 \mathrm{pmol} / \mathrm{L}$. Comparing these findings with Figure 1 it was concluded that the odds ratio of the risk of CHD for these diet groups are 5.6, 4.8 and 2.1 respectively.

1. European Vegetarian Union. (2011) [http://www.euroveg.eu/lang/en/infor/howmany.php].

2. Foods Standards Agency. (2011) [http:www.food.gov.uk/multimedia/pdfs/publicattitudestofood.pdf].

3. Selhub J. (1999) Ann Rev Nutr 19, 217-246.

4. Welch GN and Loscal J. (1998) New Eng J Med 338, 1042-1050.

5. McNulty $\mathrm{H}$ et al. (2012) Proc Nutr Soc 71, 213-222.

6. Robinson K et al. (1995) Circulation 92, 2825-2830.

7. Ubbink JB. (2001) Cam Uni Press 485-90.

8. Humphrey LL, et al. (2008) Mayo Clin Proc 83(11), 1203-1212. 